\title{
The relationship between global distress, mentalizing and well-being in a German teacher sample
}

\author{
Nicola-Hans Schwarzer ${ }^{1}$ (D) $\cdot$ Tobias Nolte $^{2,3} \cdot$ Peter Fonagy $^{2,3} \cdot$ Julia Griem $^{3} \cdot$ Ulf Kieschke $^{1} \cdot$ Stephan $_{\text {Gingelmaier }}{ }^{1}$
}

Accepted: 2 February 2021 / Published online: 26 February 2021

(C) The Author(s) 2021

\begin{abstract}
Many studies have linked global distress including higher psychological symptom severity and high levels of stress with low levels of well-being among teachers, indicating a need to identify and empirically evaluate protective factors. Mentalizing-the capacity to understand behavior in terms of intentional mental states - may be a candidate protective factor to mediate this association, enhancing well-being in the face of high levels of global distress. The present study examines whether the capacity to mentalize can buffer subjectively experienced stress and psychological symptom severity in a sample of teachers. 215 teachers completed questionnaires measuring self-rated experiences of stress, psychological symptoms, mentalizing capacities and wellbeing in a cross-sectional design. Structural equation modeling was used to test mediation effects. Our findings show that mentalizing was positively associated with well-being. In addition, mentalizing counteracted the negative influence of stress and psychological symptom severity. However, a structural equation model assessing the mediating effect of global distress on well-being via mentalizing was not significant. Therefore, the data indicate that teachers' capacity to mentalize, regardless of psychological symptom load and subjective experience of stress, has a positive impact on their well-being. The study highlights the protective function of mentalizing and forms a framework for psychological interventions to increase teachers' well-being.
\end{abstract}

Keywords Mentalizing $\cdot$ Stress $\cdot$ Well-being $\cdot$ Psychological symptomatology

\section{Introduction}

According to the transactional stress model (Lazarus \& Folkman, 1984), stress is the multifaceted result of an interaction between two systems-the individual and the environment - and is conceptualized as "the relationship between a person and the environment that is appraised by the person as taxing or exceeding his or her resources and endangering his or her well-being" (Lazarus \& Folkman, 1984, p. 21). Therefore, stress experiences represent a precursor of reduced well-being. Well-being in contrast, is described as "the state of positive functioning at its fullest range - mentally, physically and socially" (Su, Tay, \& Diener, 2014, p. 256). It includes several core contributors such as (1) enriching and supportive relationships, (2) life satisfaction and the presence

Nicola-Hans Schwarzer

nick.schwarzer@googlemail.com

Pädagogische Hochschule Ludwigsburg, Ludwigsburg, Germany

Anna Freud National Centre for Children and Families, London, UK

3 University College London, London, UK of positive feelings, (3) engagement and interest in daily activities, (4) feelings of autonomy and control, (5) purpose in life, (6) a sense of accomplishment, and (7) optimism (e.g. Diener, 1984; Ryan \& Deci, 2000; Ryff, 1995; Scheier \& Carver, 1987).

High levels of stress, increased psychological symptom severity and low well-being have been shown to be present in teachers in a range of empirical studies. Hasselhorn and Nübling (2004) investigated personal experiences of stress in more than 30,000 German employees across different fields of work. The authors found that teachers experienced particularly high stress levels compared to other employees. Similarly, when comparing more than 50,000 teachers with 35,000 employees working in other professions, Nübling et al. (2012) found that the teachers perceived their work as emotionally more difficult and reported less well-being. Additionally, teachers experienced stress-related psychological symptoms such as depressive thoughts more frequently, and consequently their self-rated well-being was poorer. These observations were further confirmed by findings of a study of 20,000 employees by Lohmann-Haislah (2012): relative to employees working in other disciplines, teachers experienced a higher symptom load. Specifically, they reported more tiredness 
and weariness, were more irritable, anxious, emotionally drained, and had higher rates of sleep difficulties.

Three consequences of high levels of global distress in teachers, encompassing psychological symptom severity and high experiences of stress, have been identified. First, high levels of global distress in teachers are associated with increased sick leave, resulting in considerable additional costs (e.g. Aktionsrat Bildung, 2014). Second, a high amount of global distress affects work performance, leading to poorer performance of teachers during lessons (e.g. Klusmann, Kunter, Trautwein, \& Baumert, 2006; Klusmann \& Richter, 2014; Klusmann, Richter, \& Lüdtke, 2016; McLean \& McDonald Connor, 2015; Shen et al., 2015). Third, the experience of global distress leads to higher subjective suffering and adversely affects well-being in teachers in a crucial way, at work (Rothland, 2013a; Nübling et al., 2012) but also in general (Meng \& D'Arcy, 2015). Therefore, there is a need to identify protective factors that could help teachers cope with high levels of global distress.

Rothland (2013b) suggested various contextual risk factors inherent to the teaching profession which may explain high symptom load and stress levels in teachers. This includes having a split workplace (school and at home) and poorly regulated working hours, extensive pedagogical challenges, obligatory work with potentially uncooperative students and/or parents, or a lack of opportunities for promotion. Further research identified classroom disruption, disciplinary problems, unmotivated or behaviourally challenging students, and interactions with colleagues, school administration, and parents as additional stressors (e.g. Chang, 2009; Hakanen, Bakker, \& Schaufeli, 2006; Nübling, Wirtz, Neuner, \& Krause, 2008; Tsouloupas, Carson, Matthews, Grawitch, \& Barber, 2010). These factors accumulate and affect distress experiences as well as well-being in several different and independent ways (Klusmann \& Waschke, 2018).

Nevertheless, Hillert, Koch, and Lehr (2013) argued that these inherent contextual do not necessarily lead to the experience of heightened levels of global distress. For example, multilevel modelling analyses in a large cohort of teachers showed that contextual factors in the school/classroom setting are not the only influences on emotional exhaustion (Klusmann, Kunter, Trautwein, Lüdtke, \& Baumert, 2008). The authors concluded that a large proportion of the variance in teachers' emotional exhaustion can be explained by several individual factors, of which contextual factors are only one. In line with this, several authors (e.g. Döring-Seipel \& Dauber, 2013; Lehr, Schmitz, \& Hillert, 2008; Schaarschmidt, Kieschke, \& Fischer, 1999) point out that healthy and stressed teachers seem to differ less with regard to objective and environmental occupational characteristics. Instead, the question arises of how they cope with the challenging factors that influence their well-being. In this context, potentially protective capacities that can be learned and improved upon via psychosocial interventions or professional training are of particular interest (Klusmann \& Waschke, 2018). This represents the rationale behind this study.

\section{Mentalizing}

The mentalizing concept integrates theoretical contributions from various disciplines such as (relational) psychoanalysis, social cognition, attachment theory, emotional awareness and theory of mind (Luyten, Campbell, Allison, \& Fonagy, 2020). Mentalizing is defined as the capacity to perceive and interpret one's own and others' behaviors in terms of intentionally motivated mental states, such as feelings, wishes, desires, thoughts, and beliefs (Fonagy \& Allison, 2014; Fonagy, Gergely, Jurist, \& Target, 2002). Mentalizing can be conceptualized as a multifaceted umbrella concept (Choi-Kain \& Gunderson, 2008) with a wide range of intrapsychic processes, encompassing second-order processes such as selfmonitoring (cognitive awareness of the self), mindfulness (emotional awareness of the self), empathy (awareness of emotional states in other people) and theory of mind (understanding other people's beliefs or perspectives). While good mentalizing allows for the adaptive integration of these processes into a coherent understanding of the self and others, difficulties in mentalizing are characterized by a poor use or integration of mental state information (Luyten et al., 2020). Critically, the process of mentalizing allows behavior to become predictable and to be perceived as meaningful, since it can be viewed as underpinned by mental states (Fonagy et al., 2002). Mentalizing is seen, like language acquisition, as a developmental achievement that is accompanied by an increasing awareness of the importance of mental states for both interpersonal and intrapsychic processes (Fonagy \& Allison, 2014).

A series of research studies, particularly in the clinical realm, have highlighted the importance of mentalizing in psychopathology (see Katznelson, 2014; Luyten et al., 2020). Impaired mentalizing has been identified as a hallmark feature of psychological illnesses such as borderline personality disorder (e.g. Németh et al., 2018), antisocial personality disorder (e.g. Newbury-Helps, Feigenbaum, \& Fonagy, 2017), and depressive disorders (e.g. Fischer-Kern et al., 2013). These and other findings have led to the development of specific psychotherapeutic strategies to improve impaired mentalizing. Evidence of the effectiveness of these strategies comes from randomized controlled trials assessing mentalization-based treatment (MBT; Bateman \& Fonagy, 2004) in individuals with borderline personality disorder, which showed that this therapy was superior in improving mentalizing, and subsequently symptom severity, compared to conventional therapies (e.g. Bateman \& Fonagy, 1999, 2008, 2009; FischerKern et al., 2015; Jørgensen et al., 2013; Levy et al., 2006; Rossouw \& Fonagy, 2012). As a result of therapy, stress- 
related symptoms also reduce (De Meulemeester, Vansteelandt, Luyten, \& Lowyck, 2018). Summing up, evidence thus suggests that impaired mentalizing, which is characteristic of various psychological illnesses, can be improved through psychotherapeutic intervention, leading to reduced psychological symptoms.

\section{Mentalizing as a Protective Capacity}

Building on the clinical relevance, a current shift towards focusing on mentalizing as a mediating, health-promoting capacity in non-clinical populations has been observed (e.g. Bateman, Campbell, Luyten, \& Fonagy, 2018; Fonagy, Luyten, Allison, \& Campbell, 2017; Luyten et al., 2020; Schwarzer, 2019). Most pertinent in this context is the idea that pre-emptive or early interventions facilitating mentalizing capacity can protect an individual from the impact of distressing factors (Brugnera, Zarbo, Compare, et al., 2020), enabling a more resilient adaptation to life stressors (Fonagy et al., 2017). This occurs through the mentalizing-mediated development of an integrated view of the self, which subsequently allows a more adaptive processing of stress-related affective arousal (e.g. Ballespi et al., 2019; Nolte et al., 2013). Fonagy et al. (2017) emphasize that holding a mental representation of potentially stressful events involving others, the meaning of their actions, the emotional impact of these on the self, and the subsequently resulting behaviour requires activating a series of intrapsychic processes that connect the individual to their social context and can buffer the impact of socially caused adversity.

In line with this, a number of studies have recently shown that good mentalizing may be a protective factor for wellbeing. A prospective longitudinal study of non-clinical adolescents showed that mentalizing predicts well-being 8 years later (Borelli et al., 2019). Moreover, Ballespi et al. (2019) found that increased mentalizing capacity was associated with a decreased frequency of somatic complaints. A mediation analysis by Chiesa and Fonagy (2014) revealed that mentalizing mediated and partially explained the direct relationship between adverse childhood experiences and psychopathology by reducing the impact of early maltreatment. Furthermore, when analysing the mentalizing ability of 500 trainee and qualified pedagogical staff, Schwarzer (2019) found that the presence of stress negatively affected subjective ratings of well-being, whereas mentalizing capacity had an indirect and positive effect on health ratings.

\section{Objective}

Considering the protective function of mentalizing capacity as well as the high levels of distress reported in teachers, the mentalizing approach provides a framework that could help teachers cope with daily stressors and psychological symptoms, thereby affecting well-being in a positive way. This is of particular interest because empirical data show that the promotion of mentalizing using mentalization-based interventions in clinical (e.g. De Meulemeester et al., 2018; Levy et al., 2006) and non-clinical samples (e.g. Adkins, Luyten, \& Fonagy, 2018; Valle et al., 2016; Welstead et al., 2018) is possible. Therefore, further evidence testing the mediating, health-promoting function of mentalizing in teachers is required. The current study aims to assess this relationship. Figure 1 shows the hypothesized mediation model, suggesting a buffering effect of mentalizing capacity when processing global distress. With reference to the summarized research above, the present study examines the following hypotheses:

(1) There will be a negative correlation between distress parameters and teachers' well-being, and a positive correlation between teachers' well-being and mentalizing.

(2) Distress parameters will predict teachers' well-being in a negative way, whereas the capacity to mentalize will have a positive impact.

(3) The effect of global distress on teachers' well-being will be mediated by mentalizing.

\section{Methods}

\section{Sample and Procedure}

Two-hundred and fifteen teachers (140 female) with a mean age of 42.4 years $(S D=10.78)$ participated in the study. There were 84 ( 54 female) special education teachers, 65 (51 female) primary school teachers, 7 ( 2 female) high school (German: Gymnasium) teachers, 18 (7 female) secondary school teachers, and 36 (26 female) teachers working in other settings. Five participants did not report demographic information. There were significant age differences among the subgroups of teachers $(F=3.96, p=0.004)$. The oldest group were the teachers in other educational settings (mean age $=$ $46.9, S D=10.73$ ) and the youngest group comprised special education teachers (mean age $=39.42, S D=11.16$ ). The entire sample had a mean of 14.12 years of work experience $(S D=$ 9.88 , range: $1-46$ years). There was a significant difference in years of work experience among the subgroups of teachers $(F=3.07, p=0.02)$. Teachers in other settings had the longest experience, with a mean $17.42(S D=11.12)$ years, whereas high school teachers had the shortest experience, with a mean of $11.71(S D=7.68)$ years. Ten participants reported a psychiatric diagnosis. There were no significant differences in the rate of psychiatric diagnosis among the subgroups of teachers $\left(\chi^{2}=8.40, p=0.080\right)$.

The data for this cross-sectional study were collected in the state of Baden-Württemberg in Germany. Participating teachers were recruited through personal connections to the school headteachers. Once a headteacher agreed, anonymized 


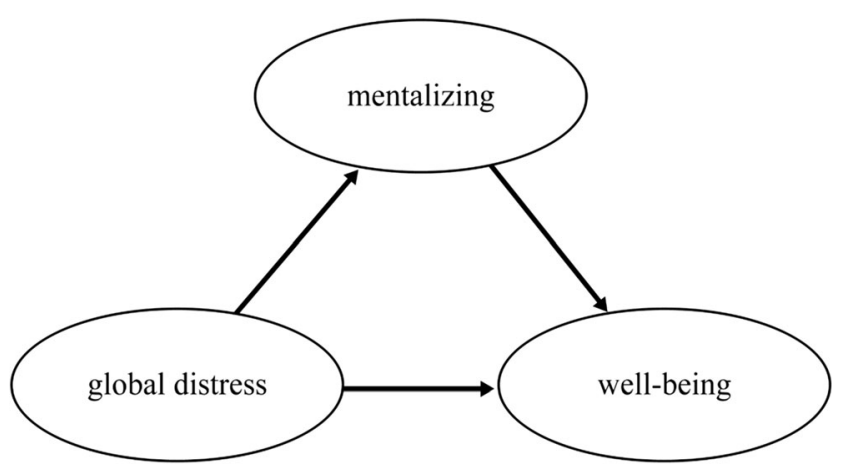

Fig. 1 Hypothesized mediation model

questionnaires were sent to the school and distributed among the teaching staff. Completed questionnaires were returned by post. Participation was voluntary and took around $10 \mathrm{~min}$. Participants could withdraw and have their data destroyed at any point. All participants provided written informed consent. In order to increase interest in the study, the anonymity of the data was prioritized, and researchers did not record the name of the school where the participant worked. Instead, participants were simply asked to report the type of school at which they worked.

\section{Measures}

Mentalizing The study assessed mentalizing as an individual's willingness and ability to interpret behaviour as a consequence of mental states (i.e., to take a mentalizing stance) The short form of the German version of the Attribution Complexity Scale (ACS) (Flechter, Danilovics, Fernandez, Peterson, \& Reeder, 1986) was used to assess participants' mentalizing capacity. The ACS has 7 items (e.g., "I don't usually put up with other people's behaviour just like that. Instead I usually think about the inner motivations for their behaviour."). The items are scored on a 7-point Likert scale from 1 (I strongly disagree) to 7 (I strongly agree). High scores indicate strong mentalizing. The internal consistency of this scale was good $(\alpha=0.85)$. The scores were normally distributed (Kolomogorov-Smirnov $p=0.651$ ).

Well-Being The Brief Inventory of Thriving (BIT) (Su et al., 2014), German version, was used to assess well-being. The BIT is a 10-item self-report shortened version of the Comprehensive Inventory of Thriving (CIT) that captures well-being in a multidimensional way, creating subscales focused on relationships, engagement, skills, sense of purpose, optimism, and subjective well-being ( $\mathrm{Su}$ et al., 2014). The BIT has been deemed a reliable, valid, and efficient screening tool (Hausler et al., 2017). The 10 items (e.g. "I am optimistic about my future") are scored on a 5-point Likert scale from 1 (I disagree completely) to 5 (I agree completely). A high score represents better well-being. The internal consistency of this scale was good $(\alpha=0.83)$. The scores were normally distributed (Kolomogorov-Smirnov $p=0.16$ ).

Distress In order to enhance the validity of the results, two instruments were used to assess distress in its multifaceted constitution. Psychological symptomatology was assessed with the SymptomChecklist-90 (Derogatis, 1994)-R (SCL). While the original questionnaire encompasses 90 items, the current study used the short version. It consists of 27 items, which are answered on a 5-point Likert scale from 0 (not at all) to 4 (extremely). There are six subscales (depressive symptoms, dysthymic symptoms, physiological symptoms, agoraphobic symptoms, social phobia, and mistrust) which are summed into one global severity index. Higher scores represent higher symptom loads. The short version is a reliable and valid instrument (Hardt, Egle, Kappis, Hessel, \& Brähler, 2004) with good internal consistency $(\alpha=0.89)$ in the current study. The scores were not normally distributed (Kolomogorov-Smirnov $p<0.001$ ). Moreover, the screening version of the Trier Inventory for Chronic Stress (TICS) (Schulz, Schlotz, \& Becker, 2004) was used to measure subjective experience of stress. The TICS consists of 12 self-report items answered on a 5-point Likert scale from 0 (never) to 4 (very often). A high score reflects greater experience of stress. The TICS is a reliable and valid measure and has been shown to be very useful for large samples. It had a very good internal consistency $(\alpha=0.91)$ in the current study. The data were normally distributed (KolomogorovSmirnov $p=0.051$ ).

Demographics As demographics age, gender, school type and years of work experience were assessed and included in all further analyses.

\section{Data Analysis}

Only $0.3 \%$ of the data were missing. The expectationmaximization algorithm (Tabachnick \& Fidell, 2012) was used to impute missing values. The dataset contained two multivariate outliers, which were identified using the Mahalanobis distance and were eliminated due to a likelihood of occurrence of $p<0.001$ (Tabachnick \& Fidell, 2012). 
Pearson's correlations were used to measure the associations between mentalizing, well-being, and distress' parameters. Three multiple linear regression analyses entering demographic information (model 1), experienced stress and psychological symptomatology (model 2) and mentalizing (model 3) were used to assess the predictive strength of age, sex, school type, years of work experience, presence of a psychiatric diagnosis, mentalizing, experience of stress, and psychological symptoms on the outcome of well-being. Residuals were analysed using a scatter plot and independence of residuals was tested using the Durbin-Watson statistic (Tabachnick \& Fidell, 2012). Multicollinearity was tested using the tolerance $(<0.01)$ and variance inflation factor $(<10)$ criteria. In order to test for mediation, structural equation modelling was employed, using a maximum likelihood estimator, as suggested by Weiber and Mühlhaus (2014). To evaluate the mod$\mathrm{el}$, the following indices of fit were used following $\mathrm{Hu}$ and Bentler (1999): (1) the $\chi^{2}$ statistic, (2) the root mean square error of approximation (RMSEA) with its $90 \%$ confidence interval (CI) and (3) the comparative fit index (CFI) with a non-significant $\chi^{2}$ statistic, RMSEA $\leq 0.06$ and $\mathrm{CFI} \geq 0.95$ as excellent fit and a non-significant $\chi^{2}$ statistic, RMSEA $\leq 0.08$ and $\mathrm{CFI} \geq 0.90$ as acceptable fit. Furthermore, owing to the large sample size $(>200)$ a significant $\chi^{2}$ statistic was expected. Mediation effects were further examined using the bootstrap CI method with 2000 bootstrap samples, and 95\% CIs were analyzed. Confirmatory factor analysis (CFA) was used to first create three latent variables representing global distress, mentalizing capacity and well-being. A general factor of global distress was created, using the TICS (Schulz et al., 2004) and the subscales of the SCL (Hardt et al., 2004), revealing excellent fit $\left(\chi^{2}(12, n=215)=19.39, p=0.080\right.$; RMSEA $=0.075$ with $90 \%$ CI [0.024, 0.142]; CFI = 0.994). Furthermore, mentalizing capacity was derived from all items of the ACS (Flechter et al., 1986), again revealing excellent fit $\left(\chi^{2}(9, n=215)=12.08, p=0.209 ;\right.$ RMSEA $=0.040$ with $90 \%$ CI [0.000, 0.092]; CFI = 0.994). Finally, well-being was calculated from all items of the BIT (Su et al., 2014). and showed good fit $\left(\chi^{2}(32, n=215)=41.67, p=0.118 ; \operatorname{RMSEA}=0.038\right.$ with $90 \%$ CI [0.000, 0.067]; CFI =0.984). In the next step, mediation effects were tested using structural equation modelling with "global distress" as the exogenous variable, "mentalizing" as mediator and "well-being" as the dependent variable. Age, gender, school type and years of work experience were included as covariates in all further analyses.

\section{Results}

Table 1 shows the descriptive variables and scores across all scales for all participants, as well as correlations between scales. Significant negative correlations were found between teachers' psychological symptomatology and their experience of stress and well-being ( $r=-0.41, p \leq 0.001 ; r=-0.32, p \leq 0.001$, respectively). A significant positive correlation was found between teachers' mentalizing capacity and well-being ( $r=0.28, p \leq$ $0.001)$. A weak positive correlation was found between stress and mentalizing $(r=0.19, p \leq 0.01)$. No significant correlations were found between psychological symptomatology and mentalizing. Age and years of work experience were not correlated with stress, well-being, or mentalizing.

Table 2 shows the results of the multiple linear regression analyses predicting well-being. All assumptions were met (i.e., normally distributed and independent residuals, homoscedasticity). There was no evidence of multicollinearity. The final regression model (model 3) was significant (medium to large effect) and revealed that $27 \%$ of variance in well-being was explained by the predictor variables (adjusted $r^{2}=0.27$, $F=9.40, p \leq 0.001)$. Psychological symptomatology $(\beta=$ $-0.32, p \leq 0.001)$ and stress $(\beta=-0.20, p \leq 0.050)$ had a significant negative effect on well-being. Mentalizing $(\beta=0.31$, $p \leq 0.001$ ) had a significant positive effect on well-being. Sex, age, school type, years of work experience, native language, and the presence of a psychiatric diagnosis were not significant predictors of well-being. In order to evaluate a potential moderation effect, we carried out another regression model with all predictors and an interaction term including mentalizing and a latent variable consisting of stress and symptomatology. This, however, led to a poorer fit (adjusted $\left.r^{2}=0.26, F=8.48, p \leq 0.001\right)$. The interaction term revealed no significance $(\beta=-0.04, p=0.490)$.

Figure 2 shows the structural equation model testing the mediating effect of mentalizing. Covariates were excluded because they were not associated with well-being and including these led to a poorer model fit. The model that used "global distress", "mentalizing", and "well-being" as latent variables fit the data well $\left(\chi^{2}(239, n=215)=350.19, p<0.001\right.$; RMSEA $=$ 0.047 with $90 \%$ CI $[0.036,0.057]$; CFI $=0.941)$. Based on 2000 bootstrap samples, a significant direct effect of global distress on well-being ( $\beta=-0.55$ with $95 \%$ CI $[-0.38,-0.69]$, $p=0.001)$ was found. Furthermore, mentalizing capacity had a significantly positive effect on well-being $(\beta=0.38$ with $95 \%$ CI $[0.19,0.53], p=0.002)$. The direct effect of global distress on mentalizing was not significant $(\beta=0.08$ with $95 \% \mathrm{CI}$ $[-0.10,0.24], p=0.403)$. Therefore, the structural equation model showed that the mediating effect reached no significance $(\beta=0.03$ with $95 \%$ CI $[-0.03,0.12], p=0.375)$. In summary, both significant effects accounted for a total contribution of $41.9 \%$ of the variance in well-being (see Fig. 2).

\section{Discussion}

The current study investigated the link between well-being, global distress, and mentalizing capacity in a sample of 215 teachers. Owing the high levels of global distress in teachers, 
Table 1 Descriptives and correlations

\begin{tabular}{llllllll}
\hline Variable & $N$ & $M(S D)$ & BIT & SCL27 & TICS & ACS & Age \\
\hline BIT & 215 & $41.42(4.27)$ & - & & & \\
SCL & 215 & $8.64(7.99)$ & $-.41^{* * *}$ & - & & & \\
TICS & 215 & $18.87(8.35)$ & $-.32 * * *$ & $.63 * * *$ & - & & \\
ACS & 215 & $34.33(7.26)$ & $.28^{* * *}$ & .07 & $.19 * *$ & - & \\
Age & 215 & $42.40(10.78)$ & .01 & .03 & -.02 & -.01 & - \\
Years in job & 215 & $14.12(9.88)$ & .03 & -.02 & -.04 & -.00 & $.89^{* * *}$ \\
\hline
\end{tabular}

BIT Brief Inventory of Thriving, SCL Symptom Checklist 27, TICS Trier Inventory of Chronic Stress - Screening Scale, ACS Attributional Complexity Scale

$* * * p<.001, * * p<.01, * p<.05$ protective factors that could help teachers cope with challenges and improve their well-being need to be identified (Klusmann \& Waschke, 2018). Mentalizing — the capacity to understand behavior in terms of intentional mental statesappears to be a promising candidate factor that could possibly mediate this association, enhancing well-being even in the presence of high levels of global distress. Thus, psychosocial interventions to enhance mentalizing capacity may be suitable for increasing teachers' well-being.

The current findings support our first hypothesis that wellbeing correlates negatively with psychological symptoms and a subjective rating of stress experiences, but positively with mentalizing capacity. These results are consistent with evidence from other clinical (Ballespi et al., 2019) and nonclinical samples (Nolte et al., 2013; Schwarzer, 2019), overall

Table 2 Results of the linear regression analyses to predict well-being in teachers

\begin{tabular}{|c|c|c|c|c|c|c|}
\hline & \multicolumn{2}{|c|}{ Model 1} & \multicolumn{2}{|l|}{ Model 2} & \multicolumn{2}{|l|}{ Model 3} \\
\hline & $\beta$ & SE & $\beta$ & SE & $\beta$ & SE \\
\hline Sex & .04 & .60 & .08 & .56 & .02 & .54 \\
\hline Age & -.10 & .60 & .02 & .05 & .04 & .05 \\
\hline School type & .10 & .19 & .07 & .18 & .10 & .17 \\
\hline Years of work experience & .10 & .06 & -.01 & .06 & -.04 & .05 \\
\hline Native language & .06 & 1,50 & .03 & 1,37 & .02 & 1,30 \\
\hline Psychiatric diagnosis & -.10 & 1,35 & -.04 & 1,23 & -.05 & 1,16 \\
\hline TICS & & & -.15 & .04 & $-.20^{*}$ & .04 \\
\hline $\mathrm{SCL}$ & & & $-.33 * * *$ & .04 & $-.32 * * *$ & .04 \\
\hline ACS & & & & & $.31 * * *$ & .04 \\
\hline $\mathrm{R}^{2}$ & .00 & & $.18 * * *$ & & $.27 * * *$ & \\
\hline
\end{tabular}

SCL Symptom Checklist 27, TICS Trier Inventory of Chronic Stress Screening Scale, ACS Attributional Complexity Scale; sex: (1) = female, (0) male; school type: (1) = school for special needs education, $(2)=$ primary school, (3) = high school, (4) = secondary school, (5) = "teacher in other settings"; native language: $(1)=$ German, $(0)=$ other; psychiatric diagnosis: $(1)=$ yes, $(0)=$ no. $* * * p<.001, * * p<.01, * p<.05$ suggesting close associations between mentalizing and wellbeing. Surprisingly, subjective ratings of stress, but not psychological symptom severity were associated with mentalizing capacity in the studied sample. According to the literature (e.g. Fonagy et al., 2002; Luyten et al., 2020; Németh et al., 2018; Newbury-Helps et al., 2017), a negative association between psychological symptoms and impairments in mentalizing capacity is to be expected, however our study failed to replicate this association. This may be explained at least partially by a lower average symptom burden in the studied sample than what is found in clinical samples (e.g. Fischer-Kern et al., 2013), indicating the need for replication of our results in mixed samples.

The multivariate linear regression analysing the impact of individual demographic factors, distress' parameters and mentalizing on well-being showed that teachers' well-being is not influenced by age, years of work experience, school type, native language, or the presence of psychiatric diagnoses. However, both distress parameters - increased psychological symptomatology and heightened subjective experience of stress - negatively predicted teachers' well-being. On the other hand, increased mentalizing positively affected well-being and therefore confirms hypothesis 2 , suggesting that mentalizing capacity may be a protective factor. These results align with clinical (Ballespi et al., 2019; Chiesa \& Fonagy, 2014) and non-clinical (Borelli et al., 2019; Schwarzer, 2019) studies, indicating the protective and health-promoting influence of mentalizing. Together, these findings suggest good mentalizing ability allows negative experiences to be metabolized and processed more adaptively (Ballespi et al., 2019; Fonagy et al., 2017), leading to an overall reduced impact of negative experiences on the individual.

Due to the potentially health-promoting role of mentalizing, confirmed by the regression results, the final hypothesis of the current study suggested that a direct impact of total stress on well-being was mediated by mentalizing capacity. Contrary to this hypothesis and much of the existing literature (e.g. Brugnera et al., 2020; Chiesa \& Fonagy, 2014; Schwarzer, 2019), the current mediation analysis showed that 


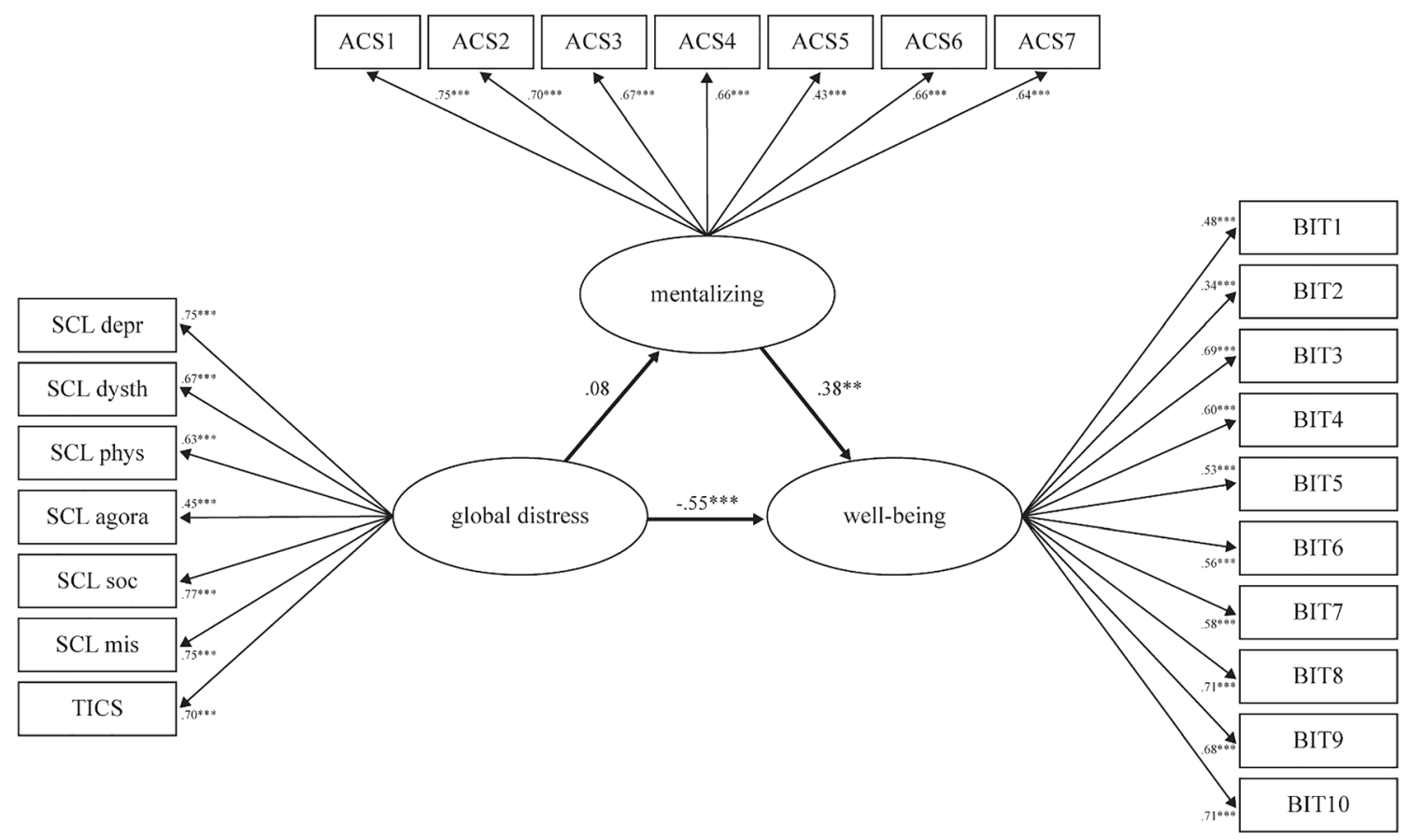

Fig. 2 Structural equation model. Notes. SCL depr $=$ depressive symptoms; SCL dysth=dysthymic symptoms; SCL phys = physiological symptoms; SCL agora = agoraphobic symptoms; SCL soc. $=$ social phobia; SCL mis = mistrust; TICS = Trier Inventory of

the indirect mediating effect of global distress on well-being via mentalizing was not significant. Therefore, considering the negative effect of global distress on well-being and the positive effect of mentalizing capacity on well-being, it must be assumed that distress and mentalizing affect teachers' wellbeing in this sample in two independent (negative and positive, respectively) ways. Teachers' mentalizing may thus not be directly associated with the processing of current distress, as our data suggest. Instead, it has an independent healthpromoting influence on teachers' well-being, indicating a protective, but rather passive role of mentalizing in the processing of distress. Consequently, this result differs from theoretical approaches which conceptualize mentalizing capacity as a mediating factor (Fonagy et al., 2017), and is contrary to recent empirical findings (e.g. Brugnera et al., 2020; Chiesa \& Fonagy, 2014; Schwarzer, 2019). This surprising result may be at least partially explained by the instruments used in the study, as well as several socio-demographic factors, that were not assessed during data collection (such as supportive relationships), indicating a need to replicate the findings in a larger sample, including both clinical and non-clinical subjects.The current findings support the idea that good mentalizing, that is the capacity to understand one's own and others' behaviour in terms of mental states, is beneficial for teachers' mental health. Teachers often report reduced well-being due to multiple stressors typical of the pedagogical field (Hasselhorn \& Nübling, 2004; Lohmann-Haislah, 2012; Nübling et al., 2012). As a consequence, increased experience
Chronic Stress - Screening Scale; ACS $=$ Attributional Complexity Scale; BIT $=$ Brief Inventory of Thriving. $* * * p<.001$, ** $p<.01$, * $p<.05$

of distress during work reduces the quality of life in general, which in turn is associated with increased costs due to sick leave, and negative impacts on work performance and the quality of teaching (e.g. Klusmann et al., 2006, 2016). Research investigating potential protective or resilience factors that reduce the impact of distress in teachers is therefore essential (Klusmann \& Waschke, 2018). Mentalizing has been shown to be a health-promoting factor (e.g. Ballespi et al., 2019; Borelli et al., 2019; Fonagy et al., 2017; Schwarzer, 2019) that is highly relevant in both clinical and non-clinical contexts. Importantly, mentalizing capacity can be modified and improved by psychotherapeutic intervention (FischerKern et al., 2015; Levy et al., 2006) and through short-term non-clinical supervision (Adkins et al., 2018; Valle et al., 2016; Welstead et al., 2018). With reference to the current study, it can be concluded that teachers' capacity to mentalize, regardless of global distress, has a positive impact on teachers' well-being.

\section{Limitations and Suggestions for Future Research}

This study extends existing evidence of the protective function of mentalizing to a non-clinical setting. Nevertheless, several limitations should be considered when interpreting these findings. The cross-sectional design confirms several theoretical hypotheses but does not allow causal inferences to be made. Furthermore, the study depends on self-report instruments, the use of which may 
lead to shared method variance as well as to biases in reporting and conclusions. A prospective or longitudinal study design using alternative methods (e.g., performance testing, physiological testing, interviews) should be conducted to replicate the current findings. The study assessed mentalizing as an individual's willingness and ability to interpret behaviour as a consequence of mental states (i.e., to take a mentalizing stance) using a self-report instrument. This approach has been criticized by some authors (e.g. Taubner \& Sevecke, 2015), and more direct measures of mentalizing exist (e.g., Fonagy, Target, Steele, \& Steele, 1998). With regard to the ACS, this instrument reflects the respondent's attitude toward taking a mentalizing stance rather than the ability to mentalize per se, so that ACS can be seen as an approximation measuring mentalizing. This may also explain why the indirect pathway of the mediation analysis did not reach significance. More specifically, we found no significant relationship between psychological symptomatology and mentalizing, and only a small positive correlation between stress and mentalizing. These findings are surprising, since psychosocial stress is associated with a temporary reduction in mentalizing capacity (Nolte et al., 2013). This observation may further support the notion that the ability to mentalize can be differentiated from the construct of holding a mentalizing stance. The sample size could be considered as a further limitation of the study, and the sample may not have been representative of all types of teachers or all types of schools and institutions. Although the experience of global distress is mostly subjective and should not be influenced by the type of school, factors such as school atmosphere, personal relationships with colleagues or the personal life situation (e.g. supportive relationships), and catchment area could covary with teachers' well-being. The current analysis did not account for these multiple levels; however, this could be incorporated into a larger, longitudinal analysis.

\section{Practical Implications}

The present study investigated the extent to which willingness to mentalize and perceive behaviour based on mental states is associated with well-being in 215 teachers, and whether it is a protective factor in light of global distress. We found that good mentalizing buffered or helped processing of the effects of distress on well-being. Furthermore, we demonstrated that the negative effect of distress and the positive influence of mentalizing on well-being were independent from each other. These findings are important in the context of high levels of distress among teachers. Furthermore, they highlight the protective function of the capacity to mentalize, which can be enhanced in teachers through interventions such as mentalization-based supervision (Adkins et al., 2018; Valle et al., 2016; Welstead et al., 2018) in order to address teachers' well-being.

Code Availability Syntax is available. Please contact the corresponding author.

Funding Open Access funding enabled and organized by Projekt DEAL.

Data Availability Data is available. Please contact the corresponding author.

\section{Declarations}

Consent to Participate All participants gave written informed consent.

Conflict of Interests The authors of this study declare that they have no biomedical or financial conflicts of interest to disclose.

Open Access This article is licensed under a Creative Commons Attribution 4.0 International License, which permits use, sharing, adaptation, distribution and reproduction in any medium or format, as long as you give appropriate credit to the original author(s) and the source, provide a link to the Creative Commons licence, and indicate if changes were made. The images or other third party material in this article are included in the article's Creative Commons licence, unless indicated otherwise in a credit line to the material. If material is not included in the article's Creative Commons licence and your intended use is not permitted by statutory regulation or exceeds the permitted use, you will need to obtain permission directly from the copyright holder. To view a copy of this licence, visit http://creativecommons.org/licenses/by/4.0/.

\section{References}

Adkins, T., Luyten, P., \& Fonagy, P. (2018). Development and preliminary evaluation of family minds: A mentalization-based psychoeducation program for foster parents. Journal of Child and Family Studies, 27, 2519-2532. https://doi.org/10.1007/s10826018-1080-x.

Aktionsrat Bildung. (2014). Psychische Belastungen und Burnout beim Bildungspersonal. Gutachten. Münster, Germany: Waxmann.

Ballespi, S., Vives, J., Alonso, N., Sharp, C., Salvadora Ramirez, M., Fonagy, P., \& Barrantes-Vidal, N. (2019). To know or not to know: Mentalization as a protection from somatic complaints. PLoS One, 14, e0215308. https://doi.org/10.1371/journal.pone.0215308.

Bateman, A., Campbell, C., Luyten, P., \& Fonagy, P. (2018). A mentalization-based approach to common factors in the treatment of borderline personality disorder. Current Opinion in Psychology, 21, 44-49. https://doi.org/10.1016/j.copsyc.2017.09.005.

Bateman, A., \& Fonagy, P. (1999). Effectiveness of partial hospitalization in the treatment of borderline personality disorder: A randomized controlled trial. American Journal of Psychiatry, 156, 15631568. https://doi.org/10.1176/ajp.156.10.1563.

Bateman, A., \& Fonagy, P. (2008). 8-year follow-up of patients treated for borderline personality disorder: Mentalization-based treatment versus treatment as usual. American Journal of Psychiatry, 165, 631-638. https://doi.org/10.1176/appi.ajp.2007.07040636.

Bateman, A., \& Fonagy, P. (2009). Randomized controlled trial of outpatient mentalization-based treatment versus structured clinical management for borderline personality disorder. American Journal 
of Psychiatry, 166, 1355-1364. https://doi.org/10.1176/appi.ajp. 2009.09040539.

Bateman, A. W., \& Fonagy, P. (2004). Mentalization-based treatment for borderline personality disorder. Oxford: University Press.

Borelli, J. L., Brugnera, A., Zarbo, C., Rabboni, M., Bondi, E., Tasca, G. A., \& Compare, A. (2019). Attachment comes of age: Adolescents' narrative coherence and reflective functioning predict well-being in emerging adulthood. Attachment \& Human Development, 21, 332 351. https://doi.org/10.1080/14616734.2018.1479870.

Brugnera, A., Zarbo, C., Compare, A. et al. (2020). Self-reported reflective functioning mediates the association between attachment insecurity and well-being among psychotherapists. Psychotherapy Research, 1-11. https://doi.org/10.1080/10503307.2020.1762946.

Chang, M. L. (2009). An appraisal perspective of teacher burnout: Examining the emotional work of teachers. Educational Psychology Review, 21, 193-218. https://doi.org/10.1007/s10648009-9106-y.

Chiesa, M., \& Fonagy, P. (2014). Reflective function as a mediator between childhood adversity, personality disorder and symptom distress. Personality and Mental Health, 8, 52-66. https://doi.org/10. 1002/pmh.1245.

Choi-Kain, L. W., \& Gunderson, J. G. (2008). Mentalization: Ontogeny, assessment, and application in the treatment of borderline personality disorder. American Journal of Psychiatry, 165, 1127-1135. https://doi.org/10.1176/appi.ajp.2008.07081360.

De Meulemeester, C., Vansteelandt, K., Luyten, P., \& Lowyck, B. (2018). Mentalizing as a mechanism of change in the treatment of patients with borderline personality disorder: A parallel process growth modelling approach. Personality Disorders, Theory, Research, and Treatment, 9, 22-29. https://doi.org/10.1037/ per0000256.

Derogatis, L. R. (1994). SCL-90-R. administration, scoring, and procedures manual. Minneapolis, MN: National Computer Systems.

Diener, E. (1984). Subjective well-being. Psychological Bulletin, 95, 542-575. https://doi.org/10.1037/0033-2909.95.3.542.

Döring-Seipel, E., \& Dauber, H. (2013). Was Lehrerinnen und Lehrer gesund hält. Empirische Ergebnisse zur Bedeutung psychosozialer Ressourcen im Lehrerberuf. Göttingen, Germany: Vandenhoeck \& Ruprecht.

Fischer-Kern, M., Doering, S., Taubner, S., Hörz, S., Zimmermann, J., Rentrop, M., Schuster, P., Buchheim, P., \& Buchheim, A. (2015). Transference-focused psychotherapy for borderline personality disorder: Change in reflective function. British Journal of Psychiatry, 207, 173-174. https://doi.org/10.1192/bjp.bp.113.143842.

Fischer-Kern, M., Fonagy, P., Kapusta, N. D., Luyten, P., Boss, S., Naderer, A., Blüml, V., \& Leithner, K. (2013). Mentalizing in female inpatients with major depressive disorder. Journal of Nervous and Mental Disease, 201, 202-207. https://doi.org/10.1097/NMD. 0b013e3182845c0a.

Flechter, G. J. O., Danilovics, P., Fernandez, G., Peterson, D., \& Reeder, G. D. (1986). Attributional complexity: An individual differences measure. Journal of Personality and Social Psychology, 51, 875884. https://doi.org/10.1037/0022-3514.51.4.875.

Fonagy, P., \& Allison, E. (2014). The role of mentalizing and epistemic trust in the therapeutic relationship. Psychotherapy, 51, 372-380. https://doi.org/10.1037/a0036505.

Fonagy, P., Gergely, G., Jurist, E., \& Target, M. (2002). Affect regulation, Mentalization, and the development of the self. London: Karnac Books.

Fonagy, P., Luyten, P., Allison, E., \& Campbell, C. (2017). What we have changed our minds about: Part 1 . Borderline personality disorder as a limitation of resilience. Borderline Personality Disorder and Emotion Dysregulation, 4, 11. https://doi.org/10.1186/s40479017-0061-9.
Fonagy, P., Target, M., Steele, H. \& Steele, M. (1998). Reflective functioning scale manual. Unpublished manuscript. University College London.

Hakanen, J., Bakker, A. B., \& Schaufeli, W. B. (2006). Burnout and work engagement among teachers. Journal of School Psychology, 43, 495-513. https://doi.org/10.1016/j.jsp.2005.11.001.

Hardt, J., Egle, U. T., Kappis, B., Hessel, A., \& Brähler, E. (2004). Die Symptom-Checkliste SCL-27. Psychotherapie, Psychosomatik, Medizinische Psychologie, 54, 214-223. https://doi.org/10.1055/s2003-814786.

Hasselhorn, H. M., \& Nübling, M. (2004). Arbeitsbedingte psychische Erschöpfung bei Erwerbstätigen in Deutschland. Arbeitsmedizin. Sozialmedizin. Umweltmedizin, 39, 568-576.

Hausler, M., Huber, A., Strecker, C., Brenner, M., Höge, T., \& Höfer, S. (2017). Validierung eines Fragebogens zur umfassenden Operationalisierung von Wohlbefinden. Diagnostica, 61, 219-228. https://doi.org/10.1026/0012-1924/a000174.

Hillert, A., Koch, A., \& Lehr, D. (2013). Das Burnout-Phänomen am Beispiel des Lehrerberufs. Nervenarzt, 84, 806-812. https://doi. org/10.1007/s00115-013-3745-4.

Hu, L., \& Bentler, P. M. (1999). Cutoff criteria for fit indexes in covariance structure analysis: Conventional criteria versus new alternatives. Structural Equation Modeling: A Multidisciplinary Journal, 6, 1-55. https://doi.org/10.1080/10705519909540118.

Jørgensen, C. R., Freund, C., Boye, R., Jordet, H., Andersen, D., \& Kjolbye, M. (2013). Outcome of mentalization-based and supportive psychotherapy in patients with borderline personality disorder: A randomized trial. Acta Psychiatrica Scandinavia, 127, 305-317. https://doi.org/10.1111/j.1600-0447.2012.01923.x.

Katznelson, H. (2014). Reflective functioning: A review. Clinical Psychology Review, 34, 107-117. https://doi.org/10.1016/j.cpr. 2013.12.003.

Klusmann, U., Kunter, M., Trautwein, U., \& Baumert, J. (2006). Lehrerbelastung und Unterrichtsqualität aus der Perspektive von Lehrenden und Lernenden. Zeitschrift für Pädagogische Psychologie, 20, 161-173. https://doi.org/10.1024/1010-0652.20. 3.161 .

Klusmann, U., Kunter, M., Trautwein, U., Lüdtke, O., \& Baumert, J. (2008). Engagement and emotional exhaustion in teachers: Does the school context make a difference? Applied Psychology, 57, 127-151. https://doi.org/10.1111/j.1464-0597.2008.00358.x.

Klusmann, U., \& Richter, D. (2014). Beanspruchungserleben von Lehrkräften und Schülerleistung. Zeitschrift für Pädagogik. Eine Analyse des IBQ-Ländervergleichs in der Primarstufe. Zeitschrift für Pädagogik, 60, 202-224.

Klusmann, U., Richter, D., \& Lüdtke, O. (2016). Teachers' emotional exhaustion is negatively related to students' achievement: Evidence from a large-scale assessment study. Journal of Educational Psychology, 108, 1193-1203. https://doi.org/10.1037/edu0000125.

Klusmann, U., \& Waschke, N. (2018). Gesundheit und Wohlbefinden im Lehrberuf. Göttingen, Germany: Hogrefe. https://doi.org/10.1026/ 02863-000.

Lazarus, R. S., \& Folkman, S. (1984). Stress, appraisal, and coping. New York, NY: Springer.

Lehr, D., Schmitz, E., \& Hillert, A. (2008). Bewältigungsmuster und psychische Gesundheit. Eine clusteranalytische Untersuchung zu Bewältigungsmuster im Lehrerberuf. Zeitschrift für Arbeits- und Organisationspsychologie, 52, 3-16. https://doi.org/10.1026/09324089.52.1.3

Levy, K. N., Meehan, K. B., Kelly, K. M., Reynoso, J. S., Weber, M., Clarkin, J. F., \& Kernberg, O. F. (2006). Change in attachment patterns and reflective function in a randomized control trial of transference-focused psychotherapy for borderline personality disorder. Journal of Consulting and Clinical Psychology, 74, 10271040. https://doi.org/10.1037/0022-006X.74.6.1027. 
Lohmann-Haislah, A. (2012). Stressreport Deutschland 2012. Psychische Anforderungen, Ressourcen und Befinden. Dortmund, Germany: Bundesanstalt für Arbeitsschutz und Arbeitsmedizin.

Luyten, P., Campbell, C., Allison, E., \& Fonagy, P. (2020). The mentalizing approach to psychopathology: State of the art and future directions. Annual Review of Clinical Psychology, 16, 1-29. https:// doi.org/10.1146/annurev-clinpsy-071919-015355.

McLean, L., \& McDonald Connor, C. (2015). Depressive symptoms in third-grade teachers: Relations to classroom quality and student achievement. Child Development, 86, 945-954. https://doi.org/10. 1111/cdev.12344.

Meng, X., \& D'Arcy, C. (2015). Coping strategies and distress reduction in psychological well-being? A structural equation modelling analysis using a national population sample. Epidemiology and Psychiatric Sciences, 25, 370-383. https://doi.org/10.1017/ S2045796015000505.

Németh, N., Matrai, P., Hegyim P., Czeh, B., Ctopf, L., Hussain, A., ... Simon, M. (2018). Theory of mind disturbances in borderline personality disorder: A meta-analysis. Psychiatry Research, 270, 143153. https://doi.org/10.1016/j.psychres.2018.08.049.

Newbury-Helps, J., Feigenbaum, J., \& Fonagy, P. (2017). Offenders with antisocial personality disorder display more impairments in mentalizing. Journal of Personality Disorders, 31, 232-255. https://doi.org/10.1521/pedi_2016_30_246.

Nolte, T., Bolling, D., Hudac, C., Fonagy, P., Mayes, L., \& Pelphrey, K. (2013). Brain mechanisms underlying the impact of attachmentrelated stress on social cognition. Frontiers in Human Neuroscience, 7, 816. https://doi.org/10.3389/fnhum.2013.00816.

Nübling, M., Vomstein, M., Haug, A., Nübling, T., Stößel, U., Hasselhorn, H.M., ... Krause, A. (2012). Personenbezogene Gefährdungsbeurteilung an öffentlichen Schulen in BadenWürttemberg - Erhebung psychosozialer Faktoren bei der Arbeit. Freiburg, Germany: Freiburger Forschungsstelle Arbeits- und Sozialmedizin.

Nübling, M., Wirtz, M., Neuner, R., \& Krause, A. (2008). Ermittlung psychischer Belastungen bei Lehrkräften - Entwicklung eines Instruments für die Vollerhebung in Baden-Württemberg. Zentralblatt für Arbeitsmedizin, 58, 312-313. https://doi.org/10. 1007/BF03346233.

Rossouw, T. I., \& Fonagy, P. (2012). Mentalization-based treatment for self-harm in adolescents: A randomized controlled trial. Journal of the American Academy of Child \& Adolescent Psychiatry, 51, 1304 1313.e3. https://doi.org/10.1016/j.jaac.2012.09.018.

Rothland, M. (2013a). Belastung und Beanspruchung im Lehrerberuf und die Modellierung professioneller Kompetenz von Lehrerinnen und Lehrern. In M. Rothland (Ed.), Belastung und Beanspruchung im Lehrerberuf. Modelle. Befunde. Interventionen (pp. 7-20). Springer VS: Wiesbaden, Germany.

Rothland, M. (2013b). Beruf: Lehrer/Lehrerin - Arbeitsplatz: Schule. In M. Rothland (Ed.), Belastung und Beanspruchung im Lehrerberuf. Modelle. Befunde. Interventionen (pp. 21-39). Springer VS: Wiesbaden, Germany.

Ryan, R. M., \& Deci, E. L. (2000). Self-determination theory and the facilitation of intrinsic motivation, social development, and well- being. American Psychologist, 55, 68-78. https://doi.org/10.1037/ 0003-066X.55.1.68.

Ryff, C. D. (1995). Psychological well-being in adult life. Current Directions in Psychological Science, 4, 99-104. https://doi.org/10. 1111/1467-8721.ep10772395.

Schaarschmidt, U., Kieschke, U., \& Fischer, A. (1999). Beanspruchungsmuster im Lehrerberuf. Psychologie in Erziehung und Unterricht, 46, 244-268.

Scheier, M. F., \& Carver, C. S. (1987). Dispositional optimism and physical well-being: The influence of generalized outcome expectancies on health. Journal of Personality, 55, 169-210. https://doi.org/10. 1111/j.1467-6494.1987.tb00434.x.

Schulz, P., Schlotz, W., \& Becker, P. (2004). TICS. Trierer Inventar zum chronischen Stress. Göttingen, Germany: Hogrefe.

Schwarzer, N. H. (2019). Mentalisieren als schützende Ressource? Eine Studie zur gesundheitserhaltenden Funktion der Mentalisierungsfähigkeit Wiesbaden, Germany: Springer VS. https://doi.org/10.1007/978-3-658-25424-7.

Shen, B., McCaughtry, N., Martin, J., Garn, A., Kulik, N., \& Fahlman, M. (2015). The relationship between teacher burnout and student motivation. British Journal of Educational Psychology, 85, 519-532. https://doi.org/10.1111/bjep.12089.

Su, R., Tay, L., \& Diener, E. (2014). The development and validation of the comprehensive inventory of thriving (CIT) and the brief inventory of thriving (BIT). Applied Psychology. Health and Well-Being, 6, 251-279. https://doi.org/10.1111/aphw.12027.

Tabachnick, B. G., \& Fidell, L. S. (2012). Using multivariate statistics (6th ed.). Boston, MA: Pearson.

Taubner, S., \& Sevecke, K. (2015). Kernmodell der Mentalisierungsbasierten Therapie. Psychotherapeut, 60, 169-184. https://doi.org/10.1007/s00278-015-0012-0.

Tsouloupas, C. N., Carson, R. L., Matthews, R., Grawitch, M. J., \& Barber, L. K. (2010). Exploring the association between teachers' perceived student misbehavior and emotional exhaustion: The importance of teacher efficacy beliefs and emotion regulation. Educational Psychology, 30, 173-189. https://doi.org/10.1080/ 01443410903494460 .

Valle, A., Massaro, D., Castelli, I., Intra, F. S., Lombardi, E., Bracaglia, E., \& Marchetti, A. (2016). Promoting mentalizing in pupils by acting on teachers: Preliminary Italian evidence of the "thought in mind" project. Frontiers in Psychology, 7, 1213. https://doi.org/10. 3389/fpsyg.2016.01213.

Weiber, R., \& Mühlhaus, D. (2014). Strukturgleichungsmodellierung. Eine anwendungsorientierte Einführung in die Kausalanalyse mit Hilfe von AMOS, SmartPLS und SPSS. Berlin: Springer.

Welstead, H., Patrick, J., Russ, T., Cooney, G., Mulvenna, C., Maclean, C., \& Polnay, A. (2018). Mentalising skills in generic mental healthcare settings: Can we make our day-to-day interactions more therapeutic? BJPsych Bulletin, 42, 102-108. https://doi.org/10. 1192/bjb.2017.29.

Publisher's Note Springer Nature remains neutral with regard to jurisdictional claims in published maps and institutional affiliations. 